\title{
Determinants of community-based health insurance implementation in west Gojjam zone, Northwest Ethiopia: a community based cross sectional study design
}

Tsega Hagos Mirach ${ }^{1}$, Getu Debalkie Demissie ${ }^{2^{*}}$ and Gashaw Andargie Biks ${ }^{1}$

\begin{abstract}
Background: In most developing countries, healthcare cost is mainly paid at the time of sickness and out-of-pocket at the point of service delivery which potentially could inhibit access. The total economic cost of illness for households is also estimated to be frequently above 10\% of household income which is categorized as catastrophic. The purpose of this study was to assess factors that determine decisions to join the community based health insurance in West Gojjam zone.

Methods: A community based cross sectional survey was conducted to collect data from 690 household heads using a multistage sampling technique. A binary logistic regression was used to identify the determinants of household decisions for $\mathrm{CBH}$ enrollment.

Results: Out of the participants, 58\% were $\mathrm{CBHI}$ members. Besides, family size ( $\mathrm{AOR}=1.17 ; \mathrm{Cl}=1.02-1.35)$, average health status (AOR =.380; $\mathrm{Cl}=.179-.805)$, chronic disease ( $\mathrm{AOR}=3.42 ; \mathrm{Cl}=1.89-6.19)$; scheme benefit package adequacy ( $A O R=2.17 ; C l=1.20-3.93)$, perceived health service quality ( $A O R=3.69 ; C l=1.77-7.69), C B H I$ awareness $(\mathrm{AOR}=4.90 ; \mathrm{Cl}=1.65-14.4) ;$ community solidarity $(\mathrm{AOR}=3.77 ; \mathrm{Cl}=2.05-6.92)$ and wealth $(\mathrm{AOR}=3.62 ; \mathrm{Cl}=1.67-7.83)$ were significant determinant factors for enrolment in the community based health insurance scheme.

Conclusion: $\mathrm{CBH}$ awareness, family health status, community solidarity, quality of service of health institutions, and wealth were major factors that most determine the household decisions to enroll in the system. Therefore, in-depth and sustainable awareness creation programs on the scheme; stratified premium- based on economic status of households; incorporation of social capital factors, particularly building community solidarity in the scheme implementation are vital to enhance sustainable enrollment. As perceived family health status and the existence of chronic disease were also found significant determinants of enrollment, the Government might have to look for options to make the scheme mandatory.
\end{abstract}

Keywords: Community based health insurance, Enrollment, Determinants, West Gojjam

\footnotetext{
* Correspondence: getud2006@gmail.com

${ }^{2}$ Department of Health Education and Behavioral Sciences, College of

Medicine and Health Sciences, University of Gondar, Gondar, Ethiopia

Full list of author information is available at the end of the article
}

(c) The Author(s). 2019 Open Access This article is distributed under the terms of the Creative Commons Attribution 4.0 International License (http://creativecommons.org/licenses/by/4.0/), which permits unrestricted use, distribution, and reproduction in any medium, provided you give appropriate credit to the original author(s) and the source, provide a link to the Creative Commons license, and indicate if changes were made. The Creative Commons Public Domain Dedication waiver (http://creativecommons.org/publicdomain/zero/1.0/) applies to the data made available in this article, unless otherwise stated. 


\section{Background}

In most developing countries, healthcare cost is mainly paid at the time of sickness and out-of-pocket (OOP) at the point of service delivery which potentially could inhibit access [1]. The share of health expenditure to households' income is also considered significant. The total economic cost of illness for households is estimated to be frequently above $10 \%$ of household income. This is potentially catastrophic: as such expenditure levels are "likely to force households to cut their consumption of other minimum needs, trigger productive asset sales or high levels of debt, and lead to impoverishment" [2].

Rural households in most developing countries are excluded from the formal insurance system. Thus, community-Based Health Insurance (CBHI) is being promoted for its potential to pool risks and resources so as to reduce households out off pocket expenditure and improve access to health care [3].

The scheme is being implemented in most low and middle income countries. However, it is continued to be challenged by low uptake, coverage, and sustainability issues. As the findings showed, a different interconnected factors at different levels (individual, institutional and policy) determine the application of CBHI schemes [4].

The Ethiopian health care system is characterized by High out-of-pocket expenditure, increased health care needs, inability to mobilize more resources for health among rural dwellers, and inability to fully recover costs of care incurred by beneficiaries [5]. Thus, the country introduced a pilot community based health insurance (CBHI) scheme in 2011. CBHI uptake was so remarkable in the country in the piloting year which was raised to $41 \%$ in one year. However, in the next year $18 \%$ of the households which enrolled in the first year withdrawing their payment [6].

Enrollment determinant factors are broadly classified as household charactertics, scheme related factors, social capital, institutional factors, and supply side factors [7]. Most studies reported that the role of education was statistically significant in determining decisions to enroll [8-10]. Studies in Tanzania and Ethiopia, on the otherhand, noted that income had a positive significant contribution to making decisions about enrolment $[9,11]$.

Raising awareness and understanding the risk pooling principle (the process of creating a common pool of money so that the financial risks entailed by certain high-risk individuals are mitigated by money from lowrisk individuals) is another vital issue to enhance enrollment. Studies conducted in different African countries such as Tanzania and Ethiopia found failure to understand the risk pooling principle and lack of information limit enrolment $[6,11]$. Besides, having a favorable policy of environment that provideds appropriate legislative frameworks, integrating CBHI schemes with government structures, and sustained technical assistance are among the vital factors for a successful implementation of the scheme [12].

In $\mathrm{CBHI}$ scheme implementation, lack of a systematic incorporation of the social context is justified for low rates of enrolment [13]. Different studies revealed that there must be social capital in the community for $\mathrm{CBHI}$ to have a long-term effect [14-16]. Scheme related factors, such as the benefit package design, premium amount, and transparency affects people's decision to enroll [17].

Despite the significance of customized designs and evidence based implementation of the scheme, only limited studies focus mainly on willingness to pay, enrolment, and dropout rates were done in Ethopia. Therefore, the aim of this study was to identify the determinants of household CBHI enrollment.

\section{Hypothesis of the study}

According to a priori theoretical ground, factors such as larger family size, poor perceived health status, good insurance awarness, adequacy of benefits provided by the scheme, quality of health service delivery, existence of good scheme regulatory and complaint handling mechanisms, good social capital, and high household wealth were assumed to increase household's probability of deciding to enroll.

\section{Methods}

\section{Study design and setting}

A Community based cross sectional study design was used. The study site is located in West Gojjam zone in Amhara region $385 \mathrm{~km}$ from Addis Ababa, northwest Ethiopia. The total population of the zone is estimated at 2,474,254 (1,220,477 male and 1,253,777 female) [18].

There are 13 rural districts and 5 town administrations in West Gojjam zone. Regarding to health service institutions; there are one government hospital, 90 health centers, 76 private health facilities (hospitals and higher clinics), and 363 health posts [19]. A community based cross-sectional study was conducted particularly in rural kebeles (the smallest administrative unit in Ethiopia) in March 2017.

\section{Study participants and data collection}

Household heads who were residents (lived for more than 6 months in the kebelles) of the selected districts were included; heads and/or spouses employed in the formal sectors were excluded.

The sample size was determined using the single population proportion formula by assuming a 58\% proportion (based on the the 2015 Ethiopian Insurance Agency pilot study, which reported that $58 \%$ of the households in the 
study area were members of the scheme) [20], a 5\% margin of error, a $95 \%$ confidence level, and 5\% non-response rate.

$$
n=\frac{Z_{a / 2}^{2} * P *(1-P)}{E^{2}}
$$

A total of 690 household heads participated in the study. A multistage sampling procedure was used to select participants. Firstly, two of the $10 \mathrm{CBHI}$ implementing districts were randomly selected. Secondly, six kebelles were randomly selected out of the two districts. Thirdly, household heads were selected by the systematic random sampling technique from each kebelle. Finally, the lottery method was used to select a number between one and the sampling interval which turned out to be 29.

A cross sectional survey was carried out by using a semi-structured questionnaire to gather data from selected representative households in the zone. The primary data was collected via an enumerator-administered questions which comprised, among others things, household characteristics, scheme related factors, the benefit package design, social capital, institutional and supply side factors which are considered to be important variables affecting household CBHI enrollment.

\section{Data quality and analysis}

The instrument was drafted in English and translated to Amharic and back to English by language experts.

Besides, to maintain its consistency, the questionnaire was pre- tested on local people living outside the selected kebelles. and cronbach's alpha average value of variables was done.

Epi-info version 3.5 was used for data entry. Descriptive statistics, such as frequency distributions, tables, and graphs were used to present the characteristics of the data. $\mathrm{Bi}$-variable analysis was performed to assess the strength of association of the independent variables with the dependent variable, and all the variables were fitted for the multivariate analysis. The effects of the several independent variables on $\mathrm{CBHI}$ enrollment decision were assessed through the multivariable analysis, and STATA 10 statistical package was used for the logistic regression model.

To estimate the strength of association between the independent variables and the CBHI enrollment odds ratio, a $95 \% \mathrm{C}$. I, and $p$-values were used.

Besides, different diagnostic tests were done, particularly goodness of fit of the model by the Hosmer and Lemeshow test; (where p-value of 0.0822 was found), Variance inflation factor (VIF) for the multicollinearity test (the mean VIF result was 1.39), and sample size sufficiency test (which found 15 sample size for each case by dividing the 690 sample by the total number of cases which in this case was 46) was also done to increase estimator accuracy and control confounding effects as logistic regression can control numereous confounders for large sample size.

The number of people included in the multiple logistic regression was 648 with a missing value of $6.3 \%$ which was treated through the imputation technique (using mean value for a continuous variables and mode for categorical variables).

\section{Operational definitions and measurement}

The scale and measurement for most of the variables used in this study were adapted from the Federal Health Insurance Agency of Ethiopia pilot study 2015 [20]. However, variables such as wealth and social capital were taken from EDHS 2011 and World Bank group respectively.

\section{CBHI awareness}

This referes to household heads knowledge of CBHI existence, its principles, and significance. It was assessed by asking the participants five sets of related questions. The Cronbach's alpha value was .722.

\section{Benefit-package design}

Refers to the sufficiency of the health services that are offered by the scheme that would be covered through out-of-pocket spending at times of sickness; and the premium amount charged. This was measured by two questions using the Likert scale with a Cronbach's alpha value of .673 .

\section{Quality of service delivery}

This includes health workers' attitude, availability of drugs, facilities/ medical equipment, waiting time, and the rapidity of the treatment's results of the health service provider; and measured via eleven Likert scale type questions. The cronbach's alpha result of this variable was .73.

\section{Scheme related factors}

Refer to transparency on scheme rules, regulation, and procedures measured through one Likert scale type question with a Cronbach's alpha value of .784.

\section{Institutional factors}

Include regulatory mechanisms, complaint handling systems, and insurance education. This variable was measured by seven Likert scale type questions. The Cronbach's alpha result of this variable was .688 .

\section{Supply side factors}

Refer to the quality of care and distance of household's homes from the nearest health facility which is measured 
by eleven Likert scale type questions with a Cronbach's alpha value of .786 .

\section{Social capital}

Includes trust, networks and group participation, social norms, and solidarity and togetherness features of the social organization of the community. Fifteen Likert scale type questions were adopted from the World Bank Group [21] to measure the variable with Cronbach's alpha value of .656.

\section{Wealth}

Refers to household assets and was measured by questions adopted from EDHS 2011 [22]. Principal Components Analysis (PCA) in STATA was used to develop the index.

\section{Results}

\section{Socio demographic characteristics of the study participants}

A total of 690 household heads with $97 \%$ response rate participated in the study. Of the participants, 598 (89.7\%) were male with a mean age of $45.4( \pm 12.09)$. The majority of respondents were Orthodox Christian by religion, and married (Table 1).

The majority of the respondents were farmers, a mean family size was $5.38( \pm 2.79), 42.7 \%$ were able to read and write, and the household wealth of $23 \%$ of the respondents was in the first quintile.

\section{Factors associated with $\mathrm{CBHI}$ enrollment}

The outcome variable (CBHI enrollment decision) was treated as a binary outcome: " 1 " for enrolled and "0" for un-enrolled households and 19 explanatory variables were considered in the econometric model. The econometrics logistic analysis showed that household family size was significantly associated with $\mathrm{CBHI}$ enrollment. As the household size increased by one unit, the likelihood to join the scheme increased by 1.17 times $(\mathrm{AOR}=$ 1.17; CI =1.02-1.35). Likewise, participants with good $\mathrm{CBHI}$ awareness were 3.77 times more likely to join the scheme compared with their counterpart $(\mathrm{AOR}=4.90$; $\mathrm{CI}=1.65-14.4)$.

The results also indicated that household with good perceived family health status were 0.38 times less likely to enroll compared with those with poor family health $(\mathrm{AOR}=.380 ; \mathrm{CI}=.179-.805)$. Similarly, household who had family members with chronic disease were 3.42 times more likely to join compared with their counterparts (AOR = 3.42; CI = 1.89-6.19) (Table 2).

In the study, scheme benefit package adequacy indicated a strong positive effect on enrollment. Household which perceived that the benefit package of the scheme was adequate were 2.17 times more likely to
Table 1 Demographic and Socio-economic characteristics of the study participants in West. Gojjam Zone, northwest Ethiopia, 2017 $(n=690)$

\begin{tabular}{|c|c|c|}
\hline Variable & Description & Frequency n (\%) \\
\hline \multirow[t]{2}{*}{ Sex } & Male & $598(89.7)$ \\
\hline & Female & $62(10.3)$ \\
\hline \multirow[t]{5}{*}{ Age } & Less than 30 years & $46(7.1)$ \\
\hline & 30-39 years & $165(25.7)$ \\
\hline & 40-49 years & $186(28.9)$ \\
\hline & $50-59$ years & $165(25.7)$ \\
\hline & 60 years and above & $80(12.5)$ \\
\hline \multirow[t]{4}{*}{ Marital status } & Married & $561(84.1)$ \\
\hline & Single & $26(3.9)$ \\
\hline & Divorced & $42(6.3)$ \\
\hline & Widowed & $24(3.6)$ \\
\hline \multirow[t]{4}{*}{ Education } & Not able to read and write & $83(15.5)$ \\
\hline & Able to read and write & $228(42.7)$ \\
\hline & Primary school [1-8] & 169 (31.6) \\
\hline & Secondary school \& above & $54(10.1)$ \\
\hline \multirow[t]{5}{*}{ Occupation } & Farmers & $636(95.4)$ \\
\hline & Merchants & $6(0.9)$ \\
\hline & Housewifes & $1(0.1)$ \\
\hline & Daily laborers & $13(1.9)$ \\
\hline & Others & $3(0.4)$ \\
\hline \multirow[t]{3}{*}{ Family size } & $\leq 3$ members & $134(20.7)$ \\
\hline & 4-6 members & $342(53)$ \\
\hline & $>6$ members & $170(26.3)$ \\
\hline \multirow[t]{5}{*}{ Household's wealth } & Poorest (1st quintile) & $148(23.2)$ \\
\hline & Poor (2nd quintile) & $11(17.4)$ \\
\hline & Medium (3rd quintile) & $129(20.2)$ \\
\hline & Rich (4th quintile) & $127(19.9)$ \\
\hline & Richest (5th quintile) & $124(19.4)$ \\
\hline
\end{tabular}

enroll compared with those who perceived inadequate benefit.

The results also revealed that respondents with good perception about the quality of health services were 3.69 times more likely to enroll in CBHI than respondents who perceived low health service quality $(\mathrm{AOR}=3.69 ; \mathrm{CI}=1.77-7.69)$. Besides, households in the fifth quintile (the richest) were 3.62 times more likely to enroll than the poorest in the first quintile $(\mathrm{AOR}=3.62 ; \mathrm{CI}=1.67-7.83)$.

In the social capital dimension solidarity was strongly associated with enrollment. Household who believed existence of good community solidarity were 3.77 times more likely to join than those who responded existence of weak community solidarity ( $\mathrm{AOR}=3.77 ; \mathrm{CI}=2.05-6.92$ ). 
Table 2 Logistic regression analysis of willingness to join CBHI in West Gojjam Zone, 2017

\begin{tabular}{|c|c|c|c|c|c|}
\hline \multirow[t]{2}{*}{ Variables } & \multicolumn{2}{|l|}{ Enrollment } & \multirow{2}{*}{$\begin{array}{l}\text { Crude OR } \\
(95 \% \mathrm{Cl})\end{array}$} & \multirow{2}{*}{$\begin{array}{l}\text { Adjusted OR } \\
(95 \% \mathrm{Cl})\end{array}$} & \multirow{2}{*}{$\begin{array}{l}\text { Marginal } \\
\text { effects }\end{array}$} \\
\hline & Yes n (\%) & No n (\%) & & & \\
\hline \multicolumn{6}{|l|}{ District } \\
\hline Jabi-tehnan & $276(63)$ & $162(37)$ & & & \\
\hline Burie & $104(48.3)$ & $111(51.7)$ & $0.55(.395, .765)$ & $.444(.257, .767)$ & -.190 \\
\hline \multicolumn{6}{|l|}{ Sex } \\
\hline Male & $355(60.5)$ & $231(39.5)$ & 1.0 & 1.0 & \\
\hline Female & 19 (31.2) & $42(68.8)$ & $0.294(1.92,5.98)$ & $1.89(.683,5.27)$ & .156 \\
\hline Age & & & $1.02(.989,1.01)$ & $.990(.970,1.01)$ & -.002 \\
\hline \multicolumn{6}{|l|}{ Religion } \\
\hline Orthodox Christian & $372(58.2)$ & $266(41.8)$ & 1.0 & 1.0 & \\
\hline Others & $2(66.6)$ & $1(33.3)$ & $1.43(.129,15.8)$ & $.610(.075,4.96)$ & -.120 \\
\hline \multicolumn{6}{|l|}{ Marital status } \\
\hline Married & 339 (61.8) & $210(38.2)$ & 1.0 & 1.0 & \\
\hline Single & $10(38.5)$ & $16(61.5)$ & $.387(.172, .869)$ & $1.71(.560,5.22)$ & .116 \\
\hline Divorced & $16(39)$ & $25(61)$ & $.396(.207, .760)$ & $1.11(.357,3.48)$ & .025 \\
\hline Widowed & $6(25)$ & $18(75)$ & $.206(.081, .529)$ & $.350(.085,1.43)$ & -.256 \\
\hline \multicolumn{6}{|l|}{ Occupation } \\
\hline Farmers & $365(58.5)$ & $259(41.5)$ & 1.0 & 1.0 & \\
\hline Others & $9(40.9)$ & $13(59.1)$ & $.491(.207,1.16)$ & $.449(.175,1.15)$ & -.196 \\
\hline Family size & & & $1.245(1.14,1.35)$ & $1.17(1.02,1.35)$ & .038 \\
\hline \multicolumn{6}{|c|}{$\mathrm{HH}$ average health status } \\
\hline Poor & $76(61.2)$ & $48(38.8)$ & 1.0 & 1.0 & \\
\hline Medium & $246(57.4)$ & $183(42.6)$ & $.849(.564,1.27)$ & $.659(.363,1.19)$ & -.096 \\
\hline Good & $57(57.5)$ & $42(42.5)$ & $.857(.501,1.46)$ & $.380(.179, .805)$ & -.235 \\
\hline \multicolumn{6}{|l|}{ chronic diseases } \\
\hline Do not exist & $105(79.5)$ & $27(20.5)$ & 1.0 & 1.0 & \\
\hline Exist & $268(53.3)$ & $235(46.7)$ & $.293(.186, .463)$ & $3.42(1.89,6.19)$ & .252 \\
\hline \multicolumn{6}{|c|}{ Scheme benefit package adequacy } \\
\hline inadequate & $318(58)$ & $230(42)$ & 1.0 & 1.0 & \\
\hline adequate & $57(57.5)$ & $42(42.5)$ & $.98(.637,1.51$ & $2.17(1.20,3.93)$ & .167 \\
\hline \multicolumn{6}{|c|}{ Institutional service quality } \\
\hline Poor & $241(56.8)$ & $183(43.2)$ & 1.0 & 1.0 & \\
\hline Medium & $115(61.5)$ & $72(38.5)$ & $1.21(.853,1.72)$ & $1.24(.744,2.07)$ & .050 \\
\hline Good & $22(55)$ & $18(45)$ & $.928(.484,1.78)$ & $1.84(.709,4.78)$ & .131 \\
\hline \multicolumn{6}{|l|}{ Health service quality } \\
\hline Poor & $141(60.8)$ & $91(39.2)$ & 1.0 & 1.0 & \\
\hline Medium & $189(55.2)$ & $153(44.8)$ & $0.797(.568,1.11)$ & $3.20(1.98,5.15)$ & .269 \\
\hline Good & $49(62.8 \%)$ & $29(37.2)$ & $1.09(.642,1.85)$ & $3.69(1.77,7.69)$ & .255 \\
\hline \multicolumn{6}{|l|}{$\mathrm{CBHI}$ awareness } \\
\hline Poor & $22(81.5)$ & $5(18.5)$ & 1.0 & 1.0 & \\
\hline Medium & $30(62.5)$ & $18(37.5)$ & $0.37(.122,1.17)$ & $2.65(.735,9.54)$ & .196 \\
\hline Good & $327(56.7)$ & $250(43.3)$ & $0.29(.111, .796)$ & $4.90(1.65,14.4)$ & .376 \\
\hline \multicolumn{6}{|l|}{ HH social participation } \\
\hline Poor & $8(57.1)$ & $6(42.9)$ & 1.0 & 1.0 & \\
\hline
\end{tabular}


Table 2 Logistic regression analysis of willingness to join CBHI in West Gojjam Zone, 2017 (Continued)

\begin{tabular}{|c|c|c|c|c|c|}
\hline \multirow[t]{2}{*}{ Variables } & \multicolumn{2}{|l|}{ Enrollment } & \multirow{2}{*}{$\begin{array}{l}\text { Crude OR } \\
(95 \% \mathrm{Cl})\end{array}$} & \multirow{2}{*}{$\begin{array}{l}\text { Adjusted OR } \\
(95 \% \mathrm{Cl})\end{array}$} & \multirow{2}{*}{$\begin{array}{l}\text { Marginal } \\
\text { effects }\end{array}$} \\
\hline & Yes n (\%) & No n (\%) & & & \\
\hline Medium & $85(57.8)$ & $62(42.1)$ & $1.02(.340,3.11)$ & $.521(.093,2.90)$ & -.157 \\
\hline Good & $286(58.3)$ & $205(41.7)$ & $1.04(.358,3.06)$ & $.748(.135,4.13)$ & -.066 \\
\hline \multicolumn{6}{|l|}{ Social norm } \\
\hline Poor & $31(59.6)$ & $21(40.4)$ & 1.0 & 1.0 & \\
\hline Medium & $173(58)$ & $125(42)$ & $.938(.515,1.70)$ & $.868(.427,1.76)$ & -.033 \\
\hline Good & $172(57.9)$ & $125(42.1)$ & $.932(.512,1.69)$ & $1.02(.506,2.09)$ & .006 \\
\hline \multicolumn{6}{|l|}{ Community solidarity } \\
\hline Poor & $75(50.3)$ & $74(49.7)$ & 1.0 & 1.0 & \\
\hline Medium & $193(63.9)$ & $109(36.1)$ & $1.74(1.17,2.60)$ & $3.02(1.17,2.60)$ & .252 \\
\hline Good & $111(55.2)$ & $90(44.8)$ & $1.21(.796,1.86)$ & $3.77(.796,1.86)$ & .282 \\
\hline \multicolumn{6}{|l|}{ Community Trust } \\
\hline Poor & $4(66.6)$ & $2(33.3)$ & 1.0 & 1.0 & \\
\hline Medium & $135(58.2)$ & $97(41.8)$ & $.696(.125,3.87)$ & $3.62(.634,20.7)$ & .280 \\
\hline Good & $240(57.9)$ & $174(42.1)$ & $.690(.125,3.80)$ & $5.65(.985,32.4)$ & .401 \\
\hline \multicolumn{6}{|c|}{ Perceived living standard } \\
\hline Poor & $351(58.8)$ & $246(41.2)$ & 1.0 & 1.0 & \\
\hline Rich & $27(50)$ & $27(50)$ & $.701(.401,1.22)$ & $1.15(.505,2.63)$ & .033 \\
\hline \multicolumn{6}{|l|}{$\mathrm{HH}$ wealth } \\
\hline quintilel(poorest) & $58(39.5)$ & $89(60.5)$ & 1.0 & 1.0 & \\
\hline quintile2 (poor) & $64(58.2)$ & $46(41.8)$ & $2.13(1.29,3.53)$ & $2.05(1.08,3.91)$ & .156 \\
\hline quintile3 (medium) & 78 (62.9) & $46(37.1)$ & $2.60(1.59,4.25)$ & $2.56(1.36,4.81)$ & .200 \\
\hline quintile4(rich) & $75(60.9)$ & $48(39.1)$ & $2.39(1.46,3.91)$ & $2.26(1.17,4.35)$ & .176 \\
\hline quintile5 (very rich) & $95(77.8)$ & $27(22.2)$ & $5.39(3.14,9.27)$ & $3.62(1.67,7.83)$ & .259 \\
\hline
\end{tabular}

*** significant at $1 \%$ confidence level ${ }^{* *}$ significant at $5 \%$ confidence level ${ }^{*}$ significant at less than $10 \%$ confidence level

\section{Discussion}

The aim of this study was to assess the determinants of enrollment for community based health insurance in west Gojam Zone, Ethiopia. In this study, the enrollment rate was found to be $58.19 \%$. Family size, health status of the family, scheme service adequacy, community solidarity, health institutions service quality, CBHI awareness, and wealth were significant determinants of households CBHI enrollment.

Household family size was a significant determinant of enrollment in the scheme. This finding is similar with those of other studies [7, 9, 11, 20, 23, 24].

Larger households were more likely to purchase the insurance than smaller ones. This was attributed to the huge financial burden that large households faced at times of risk. Besides, when many members family live together in a single unit, there may be the chance of sharing different ideas for making good decisions [25].

The result of this finding also revealed that household wealth as a determinant factor for enrolment in CBHI. This finding is in line with those of other studies $[9,11$, $23,26,27]$. As income (ablity to pay) is a critical factor in determining demand, the financial resource capacity of households and affordability of the premium are a first concern to enroll [28]. Thus, those who are in good socio-economic level would be in a better position to enroll than their counter parts.

Household scheme awareness on decision for enrollment was significant. This finding is consistent with other studies [7, 29-33]. Knowledge and understanding of insurance principles and the functioning of the CBHI facilitated both enrolment and renewal decisions. It is clear that if there is low literacy and lack of information related to $\mathrm{CBHI}$ among the community, there will be low enrolment and renewal decisions [7]. Thus, although the Government of Ethiopia has been conducting CBHI awareness creation activities through insurance agents in each district, the study indicate that as there is knowledge gap among the non-members of the scheme.

The variable on scheme benefit adequacy was also significantly associated with CBHI enrolment. This is similar to previous findings [7, 11, 30, 33]. This could be due to the direct benefits obtained from broadly defined benefit packages; as the scheme package increased, the clients 
benefit increased. The benefit package offered by CBHI schemes seemd to be globally appreciated by members. Including a new service in the health insurance scheme benefit package would positively influence enrolment [30].

In this study evidence of adverse selection was detected. The health status of household family members was negatively significant determinant of enrollment. This finding is consistent with previous findings [34, 35]. Households with more sick members were willing to enroll [24]. This could be due to the fact that people with poor health and chronic illnesses had greater perceived risk for care seeking and strong needs to join the scheme. However, this finding differed from that of a study conducted in Ethiopia [6] that has found that recent illnesses, incidence of chronic diseases, and self-assessed health status did not induce enrolment. This is perhaps a usual experience as voluntary insurance schemes are prone to adverse selection.

In this study, the quality of services of health institutions was a significant factor for enrollment decisions. This finding is in-line with other studies results $[6,33$, 34]. This might be due to the direct benefits gained from the quality of services delivered by health institutions. That is because the primary objective of joining the scheme is to get high quality health service at affordable costs, quality of health care at public facilities such as patient reception (availability of health care providers, waiting time to be seen by a medical care provider, respect and consideration displayed by caregivers), prescriptions and availability of drugs and the rapidity of treatment results are strong determinant factors for membership [30].

Solidarity which encourages members who are susceptible to risk to pulltheir resources for common use is one of the key principles of a well functioning CBHI [15]. This study also indicated that community solidarity is a significant predictor of household enrollment decisions. This is in line with other studies [32, 36, 37]. The decision to join the scheme is high for individuals who perceive the existence of good community solidarity. That is, when there is a strong community solidarity, individuals value not only their own benefits but also that of community. Thus, building social solidarity in designing $\mathrm{CBHI}$ schemes will increase acceptability and uptake [24].

\section{Strength of the study}

The study tried to comprehensively investigate the determinant factors for CBHI enrollment. Incorporating a social capital variable as a determinant factor is a particular strength of this study as it has been rarely done in the past. Moreover, the broad inclusion criteria used, the sampling technique (multi stage sampling), and the representativeness of the sample employed, we believe have confirmed the external validity of this study.

\section{Limitations of the study}

Recall bias regarding the illness history of households in the past 3 months might be a limitation of the study. As a questionnaire survey, our work is subjected to information bias which is the intrinsic nature of the instrument. Moreover, it would have been also good if the study addressed the households health care needs.

\section{Conclusion}

In this study, the CBHI enrollment rate of West Gojjam Zone was $58.19 \%$. According to the regression results, family size, health status of a family, chronic disease in the household, scheme service adequacy, community solidarity, health institutions service quality, CBHI awareness, and wealth were significant determinants of households CBHI enrollment. Furthermore, the study indicated evidence of adverse selections. Therefore, in-depth and sustainable awareness creation programs on the scheme, stratified premium based on the economic status of households, incorporation of social capital factors, particularly community solidarity in the scheme implementation are vital to enhance sustainable enrollment.

Moreover, as family health status and chronic diseases were significant determinants of enrollment. The Government may need to look for options to make the scheme mandatory.

\section{Abbreviations}

AOR: Adjusted Odds Ratio; CBHI: Community Based Health Insurance; Cl: Confidence Interval; COR: Crude Odds Ratio; OOP: Out of Pocket; UHC: Universal Health Coverage

\section{Acknowledgements}

The authors would like to thank the participants for volunteering participation in the study.

\section{Authors' contributions}

TH initiated the study concept further enriched by GAB and GDD. To the rest of the tasks,like study design, data collection, oversight, data interpretation, and manuscript writing all authors contributed equally. All authors have read and approved the manuscript.

\section{Funding}

Not applicable.

\section{Availability of data and materials}

Data that support the findings are available from the correspondence author on reasonable request.

\section{Ethics approval and consent to participate}

Ethical clearance was obtained from the University of Gondar, Institute of Public Health, and a letter of permission from the district health office. An information sheet which clearly shows the research topic, the objectives of the study, the confidentiality of the participants responses and the study benefits was prepared. Data were gathered after verbal consent was secured from participants. The review committee allowed verbal consent based on the Ethiopian ethics guideline which allow verbal consent for topics which are not sensitive and has no any risk on the participants. Participants were also informed the purpose of the study and they had every right to stop participation at any time. They were matured enough(> 18 years) to understand and to give consent. The participants were included based on voluntarism and agreement. The data collector will proceed to the 
questionnaire if he approved the participants agreement otherwise stop the interview. The procedure was approved by the review committee.

\section{Consent for publication}

Not applicable.

\section{Competing interests}

The authors declare that they have no competing interests.

\section{Author details}

${ }^{1}$ Department of Health Systems and Policy, College of Medicine and Health Sciences, University of Gondar, Gondar, Ethiopia. ${ }^{2}$ Department of Health Education and Behavioral Sciences, College of Medicine and Health Sciences, University of Gondar, Gondar, Ethiopia.

Received: 8 January 2019 Accepted: 19 July 2019

Published online: 02 August 2019

\section{References}

1. Binnendijk E. Designing community-based health insurance among rural poor in India: a novel time- and cost-effective method for data sourcing; 2014

2. Russell S. THE economic burden of illness for households in developing countries: a review of studies focusing on malaria, TB, and HIV/AIDE. Am J Trop Med Hyg. 2004;71(2):147-55.

3. Jehu-Appiah C, Spaan E, Aryeetey G, Agyepong I, Baltussen R. Household perceptions and their implications for enrolment in the National Health Insurance Scheme in Ghana. Health Policy Plan. 2011;27(3):222-33.

4. Fadlallah R, El-Jardali F, Hemadi N, Morsi RZ, Abou Samra CA, Ahmad A, et al. Barriers and facilitators to implementation, uptake and sustainability of community-based health insurance schemes in low- and middle-income countries: a systematic review. Int J Equity Health. 2018;17(1):13.

5. Mariam DH. Exploring alternatives for financing health Care in Ethiopia: an introductory review article. Ethiop J Health Dev. 2001;15(3):153-63.

6. Mebratie D, Sparrow R, Yilma Z, Getnet A, Arjun B. Dropping out of Ethiopia's community-based health insurance scheme. Health Policy and Plan. 2015;30:1296-306.

7. Dror D, Hossain S, Majumdar A, Pérez Koehlmoos T, John D, Panda P. What Factors Affect Voluntary Uptake of Community-Based Health Insurance Schemes in Low- and Middle-Income Countries? A Systematic Review and Meta-Analysis. PLoS One. 2016;11(8): https://doi.org/10.1371/journal.pone. 0160479 .

8. De Allegri M, Sanon J, Sauerborn R. Understanding consumers'preferences and decision to enrol in community-based health insurance in rural West Africa. Health Policy. 2006;76:58-71.

9. Kebede A, Gebreslassie M, Yitayal M. Willingness to pay for community based health insurance among households in the rural community of Fogera District, north West Ethiopia. Int J Econ Finance Manag Sci. 2014;2(4):263-9.

10. Bendig M, Thankom A. Enrolment in micro life and health insurance: evidences from Sri Lanka; 2011.

11. Macha J, Kuwawenaruwa A, Makawia S, Mtei G, Borghi J. Determinants of community health fund membership in Tanzania: a mixed methods analysis. BMC Health service research. 2014;14:538.

12. Feleke S, Mitiku W, Zelelew Z, Ashagari H. Ethiopia's community-based health insurance: a step on the road to universal health coverage; 2015.

13. Philipa M, Pascal N. Solidarity in community-based health insurance in Senegal: rhetoric or reality? 2015.

14. Akuoko K. Social capital and Ghana's National Health Insurance Scheme: understanding informal sector participation: Masters thesis of Lund University; 2014. https://lup.lub.lu.se/student-papers/search/publication/45 00285 .

15. Donfouet HPP, Mahieu P-A. Community-based health insurance and socia capital: a review. Heal Econ Rev. 2012;2(1):5.

16. Chen K, Daukste R, Przybyl A, Fechter N. Trust, Community-Based Health Insurance and Enrollment Rates; 2012.

17. De Allegri M, Sanon M, Sauerborn R. "To enrol or not to enrol?" a qualitative investigation of demand for health insurance in rural West Africa. Soc Sci Med. 2006;62(6):1520-7.
18. Motbainor A, Worku A, Kumie A. Level and determinants of food insecurity in east and west Gojjam zones of Amhara region, Ethiopia: a community based comparative cross-sectional study. BMC Public Health. 2016;16(1):503.

19. Senedu BG, Solomon AY, Gunnar AB. Qualitative assessment of challenges in tuberculosis control in west Gojjam zone, Northwest Ethiopia: health workers' and tuberculosis control program coordinators' perspectives. Tuberc Res and Treat. 2016;2016:2036234. https://doi.org/10.1155/2016/2 036234 .

20. EHSA. Evaluation of community-based health insurance pilot schemes in Ethiopia. 2015.

21. Group WB. Measuring social capital: an integrated questionnaire. 2003.

22. CSA. Ethiopian demographic health survey. 2011.

23. Gobir A, Abubakar AO, Joshua A. Determinants of Willingness to Join Community- Based Health Insurance Scheme in a Rural Community of North-Western Nigeria. AJHE-2016-0002 E PUBLICATION AHEAD OF PRINT, No of pages:9; https://creativecommons.org/licenses/by/4.0/.

24. Adebayo EF, Uthman AU, Wiysonge CS, Stern EA, Lamont KT, Ataguba JE. A systematic review of factors that affect uptake of communitybased health insurance in low-income and middleincome countries. BMC Health serv res. 2015

25. Jude A, Atanga S, Falang C, Nso E. Factors associated with Non Enrollment into Community Based Health Insurance Schemes in the Bamenda Health District, Cameroon. Int J Public Health Epidemiol Res. 2018;4(2).

26. Usman AB. Willingness to Pay For Community Based Health Care Financing Scheme: A Comparative Study among Rural and Urban Households in Osun State, Nigeria. J Dent Med Sci. 2013;5(6).

27. Dixon J. Determinants of Health Insurance Enrolment in Ghana's Upper West Region [Dissertation ]; 2014.

28. Wang H, Zhang L, YIP W, Hisea W. Adverse selection i a voluntary rural mutual health care health insurance care in China. SOCSci Med. 2006; 63:1236-45.

29. Basaza R, Criel B, Van der Stuyft P. Community health insurance in Uganda: why does enrolment remain low? A view from beneath. Health Policy. 2008; 87(2):172-84.

30. Jacques $D$, Julie F. Community-based health insurance schemes in subSaharan Africa: which factors really influence enrolment? Institute of Human and Social Sciences, University of Liege. Belgium: Centre for Social Economy; 2008.

31. Criel B, Waelkens MP. Declining subscriptions to the Maliando mutual health organisation in Guinea-Conakry (West Africa): what is going wrong? Soc Sci Med. 2003;57(7):1205-19.

32. Jacques J, Walburga N, Joko YA, JMN O, JJR B. Community-based health insurance knowledge, concern, preferences, and financial planning for health care among informal sector workers in a health district of Douala, Cameroon. Pan Afr Med J. 2013.

33. Nair D. Determinants of Enrollment in Comprehensive Health Insurance Scheme and Implementation Challenges: A Study in Kerala, South India. Health Sci J. 2015;10(1:8)

34. William F, Ichoku HE, Ataguba JE. Paying for community based health insurance schemes in rural Nigeria: the use of inkind payments. Afr Rev Money Financ Bank. 2010.

35. Mirko Bendig TA. Enrolment in micro life and health insurance: evidences from Sri Lanka*; 2011.

36. Schneider P, Diop F. In: Alexander S, editor. Synopsis of results on the impact of community- based health insurance on financial accessibility to health Care in Rwanda. Bethesda: The International Bank for Reconstruction and Development / The World Bank; 2001.

37. Wiesmann D, Johannes J. The Emerging Movement of Community Based Health Insurance in Sub-Saharan Africa: Experiences and Lessons Learned. Afr Spectr. 2000;35(2).

\section{Publisher's Note}

Springer Nature remains neutral with regard to jurisdictional claims in published maps and institutional affiliations. 